\title{
Sistemas de emprego, estratégias de gestão e instituições do trabalho*
}

David Marsden

Tradução de Guilherme Xavier Sobrinho

Introdução

Por muito tempo, nosso pensamento sobre as relações de trabal ho e sobrea gestão dos recursos humanos esteve condicionado pelo modelo da negociação coletiva e pelo que se presumia ser o seu contrário, a negociação individual entre trabal hadores e empregadores. Enquanto a negociação coletiva referia-se ao estabelecimento conjunto de regras institucionais, a gestão de recursos humanos estava correntemente associada à negociação de tipo individual, em que os trabalhadores se viam confrontados com regras determinadas pelas gerências e oferecidas na forma de "pegar ou largar". Aceitar essa percepção leva a contrapor governança conjunta e ação gerencial unilateral. N estaúltima, a gerência évista como dotada de um grau deliberdade, ainda que variável, na definição da regulamentação do trabalho e dos sistemas administrativos no local detrabalho. Q uando se toma, por exemplo, a tipologia desistemas de gestão de recursos humanos nos locais de trabal ho compilada por Sherer e Leblebici em 2001 (ver Q uadro 2), podem-se considerar os gerentes bastante livres para escolher entre os diferentes modelos, de acordo com seus objetivos comerciais.

N este artigo, arguo que essa concepção é equivocada e que precisamos atentar para a dinâmica da relação de emprego, tratando-a como uma instituição social que deve satisfazer as exigências das duas partes quea adotam,

* Esteartigo éuma versão revista elevemente reduzida do capítulo que acaba de ser publicado em Bruce Kaufman (org.), Theoretical perspectiveson work and theemployment relationship. Industrial Relations Research Association, Champaign, IL, 2004. 
as firmas e os trabal hadores. $\mathrm{N}$ a primeira seção, examino a estrutura da relação de emprego eos requisitos que ela precisa satisfazer para setornar viável.

A relação de emprego e as regras de trabalho

A relação de emprego é a instituição social e econômica central nos mercados de trabalho e 0 alicerce da firma moderna como organização empregadora. Ela resolve um problema de coordenação bastante difícil: como assegurar os ganhos que derivam da cooperação entre partes autointeressadas, dado que cada uma delas sabe mais do que a outra a respeito de aspectos importantes de seu trabalho comum e que a separação entre elas é custosa.

D urantea maior parte do século XIX, a subcontratação funcionou bem,

1. Havia, sem dúvida, outros problemas relativos ao risco moral, notadamenteatendência a danificar o capital do empreendedor, a rebaixar a qualidade e asfreqüentesdiscordâncias sobre o uso de matérias-primas. Pelo lado dos empregadores, haviaafreqüenterelutânciadeproporcionar trénamento (cf., por exemplo, Slichter, 1919). nos casos em que o produto podia ser facilmente definido e monitorado ${ }^{1}$. Entretanto, ela atingiu seus limites à medida que a mudança técnica e a crescente complexidade da produção levaram as firmas a desejar um controle mais direto sobre o processo de trabalho e a definir as tarefas de forma mais articulada com suas próprias necessidades organizacionais. I sso significava habilitar-se a redefinir as tarefas prescritas aos trabal hadores sem nenhuma renegociação ou com uma negociação muito restrita. Para esse fim, era necessária uma nova forma contratual: a relação de emprego por tempo indeterminado.

Para os trabal hadores que encarassem com desconfiança as intenções de potenciais empregadores, um contrato por tempo indeterminado pareceria uma porta segura para a exploração e, assim, el e somente poderia tornar-se interessante se contivesse várias proteções. C oase entendeu o sentido essencial: o contrato por tempo indeterminado dá aos empregadores a autoridade para definir as tarefas dos trabal hadores ex post, "dentro de certos limites" (cf. Coase, 1937). Esses limites não podem ser estabelecidos por meio de descrições exaustivas dos cargos, com complexas cláusulas contingenciais (cf. Williamson, 1975). Além do custo de redigir tais contratos, eles não funcionariam, uma vez que seu próprio nível de detalhamento viria a criar um inesgotável terreno para barganha em relação ao posto de trabaIho. A solução, que surgiu gradualmente, foi apelar para certos tipos de regras de transação, ou regras de trabal ho, com vistas a identificar os limites da autoridade gerencial e das obrigações dos empregados. Para se tornarem efetivas, essas regras deveriam ser suficientemente simples para que trabaIhadores comuns e seus gerentes de linha pudessem aplicá-las sem a neces- 
sidade da ajuda dos departamentos de pessoal e das assessorias jurídicas. As primei ras dessas regras tenderam a identificar certos tipos de tarefas, seja pela sua complementaridade, como no caso das regras dos "postos de trabalho", comuns nas formas francesa e norte-americana de taylorismo, seja pelas ferramentas e materiais associados a certas tarefas, como foi usual nas regras de demarcação de especialidades (regras de "território do cargo"), nos Estados U nidos e na Grã-Bretanha. Embora o taylorismo tenha sido originalmente uma invenção gerencial, como os trabalhos de campo de C rozier eSlichter et al. demonstraram tão bem, os postos de trabal ho transformaram-se rapidamente em um mecanismo defensivo para os trabal hadores (cf. Crozier, 1963; Slichter et al., 1960). D efinindo-se seus cargos, delimitam-setambém suas obrigações. $M$ ais recentemente, as regras de trabalho depositaram um foco maior nas funções do que nas tarefas individuais. Embora sejam mais flexíveis, tais regras também requerem níveis mais altos de confiança e relações mais complexas entre grupos de trabal ho e gerência. Exemplos bem conhecidos podem ser encontrados na organização flexível do trabalho de grandes firmas japonesas, nas quais, como será discutido a seguir, a regra de "hierarquia de competências" normalmente rege a distribuição de tarefas no interior dos grupos de trabalho (cf. Koike, 1977; Yamanouchi e 0 kazaki-Ward, 1997). D e modo similar, na Alemanha, a regra de "qualificação" geralmente distribui o trabalho de acordo com as habilidades que ele requer (cf. Sengenberger, 1987). Essas duas últimas regras estabelecem uma relação muito mais frouxa entre as tarefas e os cargos dos trabalhadores, aprimorando a flexibilidade de tarefas. Isso ocorre porque seu foco são as funções, relacionadas seja às necessidades de produção, seja às habilidades dos trabalhadores. A legislação trabalhista e os acordos coletivos ajudaram a reforçar essas regras de trabalho.

\section{Uma tipologia das regras de transação}

Q uatro grandes tipos de regras de emprego podem também ser derivados logicamente dos requisitos para uma forma viável de contratação. Eles têm, portanto, o status especial de "regras constitutivas". Para se chegar a eles é preciso considerar as condições suficientes e necessárias que tais regras devem cumprir para que haja uma relação viável ao longo do tempo. Parto do princípio de que as firmas e os trabalhadores são basicamente auto-interessados e sujeitos a uma racionalidade limitada. $\mathrm{H}$ á, ainda, importantes assimetrias informacionais entre as duas partes; ambas deparam- 
se com custos, caso rompam a relação; e cada uma sabe que o seu próprio interesse e 0 da outra parte têm uma intersecção, mas não são idênticos. Existe, portanto, espaço para que qual quer uma das partes se comporte de modo oportunista, uma vez iniciada a relação, e ambas estão atentas a isso.

A chave para as vantagens econômicas relativas do contrato de emprego repousa no espectro de definições ex post das incumbências do trabal hador uma vez estabelecida a relação de emprego, em comparação com as especificações ex ante do produto do trabalho ou das tarefas requeridas no caso do auto-emprego. Fazer cumprir contratos que se originam no mercado aberto, como no caso do auto-emprego, torna-se relativamente fácil, já que os termos são acordados antecipadamente e as partes têm interesse em assegurar que seu grau de ambigüidade seja pequeno. A situação é bastante diferente no caso da relação de emprego por tempo indeterminado, que se assemelha mais a um acordo para trabal har junto, ainda que sob a direção do empregador, do que a uma troca mercantil. O s custos da desistência podem ser consideráveis para ambas as partes: se mais não fosse, porque a procura de trabalho e o recrutamento são caros; e esses custos elevam-se nos casos em que há investimento significativo em qualificações específicas à firma ou em outros similares. M uitos ganhos potenciais, particularmente para os empregadores, derivam do tempo indeterminado dessa relação. Evitam-se os custos e a rigidez de definir ex ante as tarefas e a produção, e as firmas não precisam conhecer o cronograma exato de suas necessidades de determinados tipos de trabal ho. Coase (1937) eSimon (1951) desenvolveram os diferentes aspectos desses benefícios em seus dois famosos artigos; Slichter et al. (1960) e W illiamson (1975), de modos diferentes, mostram os custos de se tentar trabal har com tarefas e prescrições de trabalho estreitamente definidas; e Crozier (1963) analisa os efeitos perversos de definir tarefas de forma excessivamente detalhada. Isso ajuda a explicar por que, mesmo que haja uma possibilidade real de escolha, nove em cada dez trabalhadores das economias industriais avançadas engajam-se como empregados (cf. O ECD , 1992, cap. 4).

Limites à autoridade gerencial são essenciais, e eles podem ser estabelecidos de forma mais efetiva por meio de algum tipo de regra. Precisamos, assim, analisar quais são os atributos suficientes e necessários de tais regras, que sustentem uma relação de emprego viável, a qual será livremente escoIhida em detrimento de sua principal alternativa, o auto-emprego regido por um contrato de vendas. Considerados em conjunto, esses atributos são representados pelos imperativos de eficiência e de obrigatoriedade. 
U ma condição suficiente para que trabal hadores e firmas escolham cooperar por meio de uma relação de emprego équeela seja mutuamentebené fica, comparada com suas alternativas. O s argumentos de Coase (1937) e Simon (1951) nos abrem parte do caminho, ao mostrar os ganhos gerais que podem ocorrer, na comparação com a principal alternativa - algum tipo de contrato de vendas. Entretanto, isso não éo bastante, já queépossível que uma das partes venha a tentar se apropriar de todos os ganhos. Dados os custos de desistência com que cada qual se confronta na relação, a parte que perde pode, não raro, encontrar-se em pior situação caso isso aconteça. D essa forma, uma condição necessária éa existência de uma regra queassegureo ganho de ambasas partes; em outras pal avras, quetorne clara a extensão das obrigações dos empregados ante seus empregadores, de modo que elas possam ser cobradas. A menos que isso seja garantido, uma parte ou outra irá recusar seu engajamento na relação. Entretanto, a obrigatoriedade não é suficiente por si mesma. As tarefas poderiam ser atribuídas em função da cor dos ol hos dos empregados. N esse sentido, as regras a que eles estão compelidos devem ser, também, produtivamente eficientes, definindo obrigações de um modo tal que as competências dos empregados venham ao encontro das exigências do cargo. Efetivamente, a regra potencializa o "valor adicionado" da relação de emprego, organizando o processo de treinamento e os sistemas de classificação de cargos.

Satisfazer conjuntamente os imperativos de obrigatoriedadee de eficiência é necessário e suficiente para assegurar uma relação de emprego viável. $D$ isso resulta que se podem encarar esses dois imperativos como a base para uma classificação exaustiva das regras de emprego, dados os princí pios básicos da abordagem de C oase-Simon. D emaneira geral, as regras de emprego podem satisfazer cada imperativo por meio de uma entreduas formas, eisso funda a tipologia de regras apresentada no Q uadro 1.

$\mathrm{H}$ á duas grandes abordagens pelas quais as regras de emprego estabele cem a obrigatoriedade das prescrições de trabalho. Elas podem focalizar diretamente os atributos das tarefas individuais detrabal ho ou podem fazêlo indiretamente, no interior do processo da produção ou da prestação de serviço. Um exemplo famoso da primeira situação, muito difundido em ambientes de trabalho altamente qualificado, é a identificação de tarefas que pertencem a "territórios de cargos" específicos a partir das ferramentas ou materiais utilizados: "asferramentas da atividade". Regras de tal modo simples oferecem uma forma bastante robusta de delimitar as fronteiras dos cargos de um grupo de trabalhadores e determinar onde se iniciam as de 
outro. No âmbito do trabalho de profissionais, em quea distinção das ferramentas utilizadas é menos proeminente, as frontei ras são muitas vezes traçadas a partir da identificação de operações-chave, que devem ser executadas apenas por aqueles que possuam uma qual ificação específica. I gualmente famosa, e comum tanto em ambientes deescritório como no chão defábrica, é a regra do "posto de trabalho", segundo a qual as tarefas são agrupadas de acordo com complementaridades na produção e atribuídas exclusivamente a estações individuais de trabal ho, pelas quais trabal hadores individuais são responsáveis. U sualmente, nenhuma dessas regras é imposta de forma rígida, maso elemento importanteé quetodos sabem que elas podem ser invocadas caso as relações de trabal ho se deteriorem. D esse modo, a gerência tende a impor à risca as regras de trabal ho apenas em inspeções periódicas, quando os esforços parecem estar tomando uma direção errada. "Trabal har segundo a regra" é, nesse sentido, uma forma de pressão tática enão o método normal de trabalho.

QUADRO 1

O s Imperati vos Contratuais e as Regras Comuns de Emprego

\begin{tabular}{|c|c|c|c|}
\hline & & \multicolumn{2}{|c|}{ IMPERATIVO DE EFICIÊNCIA } \\
\hline \multirow{2}{*}{\multicolumn{2}{|c|}{ IMPERATIVO DE OBRIGATORIEDADE }} & \multicolumn{2}{|c|}{ DEMANDAS DO CARGO IDENTIFICADAS POR: } \\
\hline & & $\begin{array}{l}\text { ABORDAGEM } \\
\text { DA PRODUÇÃO }\end{array}$ & $\begin{array}{c}\text { ABORDAGEM } \\
\text { DO TREINAMENTO }\end{array}$ \\
\hline \multirow[t]{2}{*}{$\begin{array}{l}\text { O FOCO NO CRITÉRIO } \\
\text { DA OBRIGAÇÃO }\end{array}$} & Centrado na tarefa & $\begin{array}{l}\text { Regra do "posto } \\
\text { de trabalho" }\end{array}$ & $\begin{array}{l}\text { Regra do "território } \\
\text { do cargo"/"ferramentas } \\
\text { do ofício" }\end{array}$ \\
\hline & $\begin{array}{l}\text { Centrado nas funções/ } \\
\text { procedimentos }\end{array}$ & $\begin{array}{l}\text { Regra da "hierarquia } \\
\text { de competências" }\end{array}$ & Regra da "qualificação" \\
\hline
\end{tabular}

A outra abordagem ao imperativo da obrigatoriedade consiste em atribuir tarefas de trabal ho tomando por base as funções. Estas, na maioria das vezes, transcendem os cargos dos trabal hadores individuaise, assim, dependem fortemente de uma dinâmica estável no âmbito dos grupos de trabaIho. $\mathrm{H}$ á evidências de que uma regra de ordenamento baseada na senioridade ou na competência pode dar sustentação a uma alocação flexível de tarefas no interior de um grupo detrabal ho (cf. M arsden, 1999, cap. 2). D o mesmo modo, competências reconhecidas podem ser usadas como critério para atribuir tipos de trabalho que possuem demandas técnicas similares. Compelir à obrigação com base em regras centradas nas funções é mais engenhoso do que com base em regras centradas nas tarefas, que requerem um 
grau mais alto de cooperação entre trabalhadores e gerências. Entretanto, essas regras são mais vulneráveis à quebra de confiança, e não se sustentam em qualquer rede de proteção que assegure um mínimo de responsabilização, como no caso das regras associadas a tarefas; essa vulnerabilidadeéum forte incentivo a que os empregadores se comportem cooperativamente.

Para queo imperativo de eficiência seja satisfeito, a atribuição de tarefas pode ser organizada de acordo com complementaridades, seja na produção, seja no treinamento, constituindo assim as abordagens da produção e do treinamento. Elas divergem, basicamente, em função das diferentes estruturas de custos de treinamento informal no trabal ho, de um lado, ede instrução formal externa, de outro. A primeira tem baixos custos iniciais, mas que se elevam sensivelmenteà medida que a proporção de treinandos aumenta. $A$ segunda tem altos custos iniciais, em função do investimento em instalações especiais para o treinamento, mas o custo médio por treinando édecrescente. A organização do trabalho de acordo com complementaridades da produção conduz ao queW illiamson chamou de cargos "idiossincráticos", ao passo que a meta de maximizar a utilização de treinamentos custosos leva as firmas a agrupar tarefas de acordo com seus requisitos de treinamento. Formas intermediárias, a meio caminho entrea abordagem da produção e a do treinamento, tendem a ser instáveis, gravitando, mais cedo ou mais tarde, para uma ou outra daquelas concepções (cf. M arsden, 1999).

As regras de emprego e as estratégias de gestão de recursos humanos no local de trabalho

A partir de um amplo balanço das pesquisas sobre estratégias de gestão de recursos humanos, Scherer eL eblebici (2001) delinearam um elenco dos tipos comuns de sistemas de gerenciamento de pessoal nos locais de trabaIho, identificados com base nessa literatura. São eles: 0 de baixos salários, 0 de gestão de recursos humanos/alto compromisso, o de orientação japonesa e 0 baseado em equipes. $0 \mathrm{~s}$ autores fundamentaram-se largamente no le vantamento internacional conduzido por Katz e Darbishire (2000) e nos trabalhos de Baron et al. (1996 e 1999) sobre os Estados Unidos. No seu estudo, Katz e $D$ arbishire identificam ainda um modelo burocrático, com variantes sindical ou não sindical. Além desses, pode-se construir também um tipo adicional de sistema, com base nas pesquisas sobre 0 trabalho por projeto nas atividades de mídia enos setores da tecnol ogia de informação (cf. Tolbert, 1996; Baumann, 2003; H aunschild, 2003, por exemplo). Todos es- 
ses tipos são sistematizados no Q uadro 2. No que concerne à análise da relação de emprego, eles podem se dividir em duas categorias mais amplas, dependendo da forma como a autoridadegerencial atribui as tarefas: se elas são definidas a partir dos cargos dos indivíduos, como comumente ocorre nos sistemas "de baixos salários" e "burocráticos", ou se são definidas em termos mais abstratos, funcionais, como no caso dos sistemas de alta performance. Acredito que as primeiras pertencem ao grupo das estratégias "centradas em tarefas", enquanto as últimas se constituem em estratégias "centradas em funções".

U ma característica-chave do sistema "burocrático" é que as tarefas de trabal ho se encontram subdivididas em uma série de cargos e os trabalhadores são destinados individualmente a esses cargos, devendo cada qual responder pelo desempenho em um determinado posto detrabalho. M aurice et al. (1988) descrevem essa forma de responsabilização individual como um dos traços definidores da organização taylorista do trabal ho na França, o que pode ser estendido para a organização taylorista do trabalho em muitos outros países, como Estados U nidos (cf. Cole, 1994). Essa abordagem fornece uma solução para o problema de estabelecer limites perceptíveis à autoridade das gerências na prescrição do trabalho. $\mathrm{H}$ avendo uma série de postos de trabalho, cada qual com seu próprio conjunto discreto de tarefas, os trabalhadores sabem em que ponto seus cargos e suas obrigações para com os empregadores terminam e onde começam os dos outros trabalhadores. Em um estudo sobrea introdução denovos métodosflexíveis de trabal ho em um ambiente desse tipo, Clark (1993) constatou que muitos trabal hadores estavam desgostosos com o novo arranjo, uma vez que a eliminação das fronteiras claras entre os cargos os havia exposto à ameaça de sanções por parte da gerência, por não terem feito seu trabalho adequadamente. $\mathrm{Na}$ mesma linha, em um estudo sobre formas flexíveis de trabal ho na França, D ugué (1994) registrou que a nova ambigüidade referente aos papéis no trabal ho e às relativas competências fez com que os trabal hadores se sentissem expostos a sanções arbitrárias das gerências por mau desempenho. Koike também enfatizou o medo dos trabalhadores, sob sistemas mais flexíveis,

2. D iscussão em seminário sobre seu trabaIho decampo em plantasindustriaisno Japão e nos Estados Unidos (Tóquio, jun. 2000). de serem expostos ao favoritismo das gerências².

O sistema burocrático também simplificou o monitoramento, pelas gerências, da performance do trabalhador. Como Reynaud (1992) assinalou, a simplificação e a codificação dos cargos permitiram que a produção fosse mais facilmente definida e quantificada. Como é sabido, quando um cargo contém múltiplas tarefas, algumas facilmente quantificadas e monitoradas 


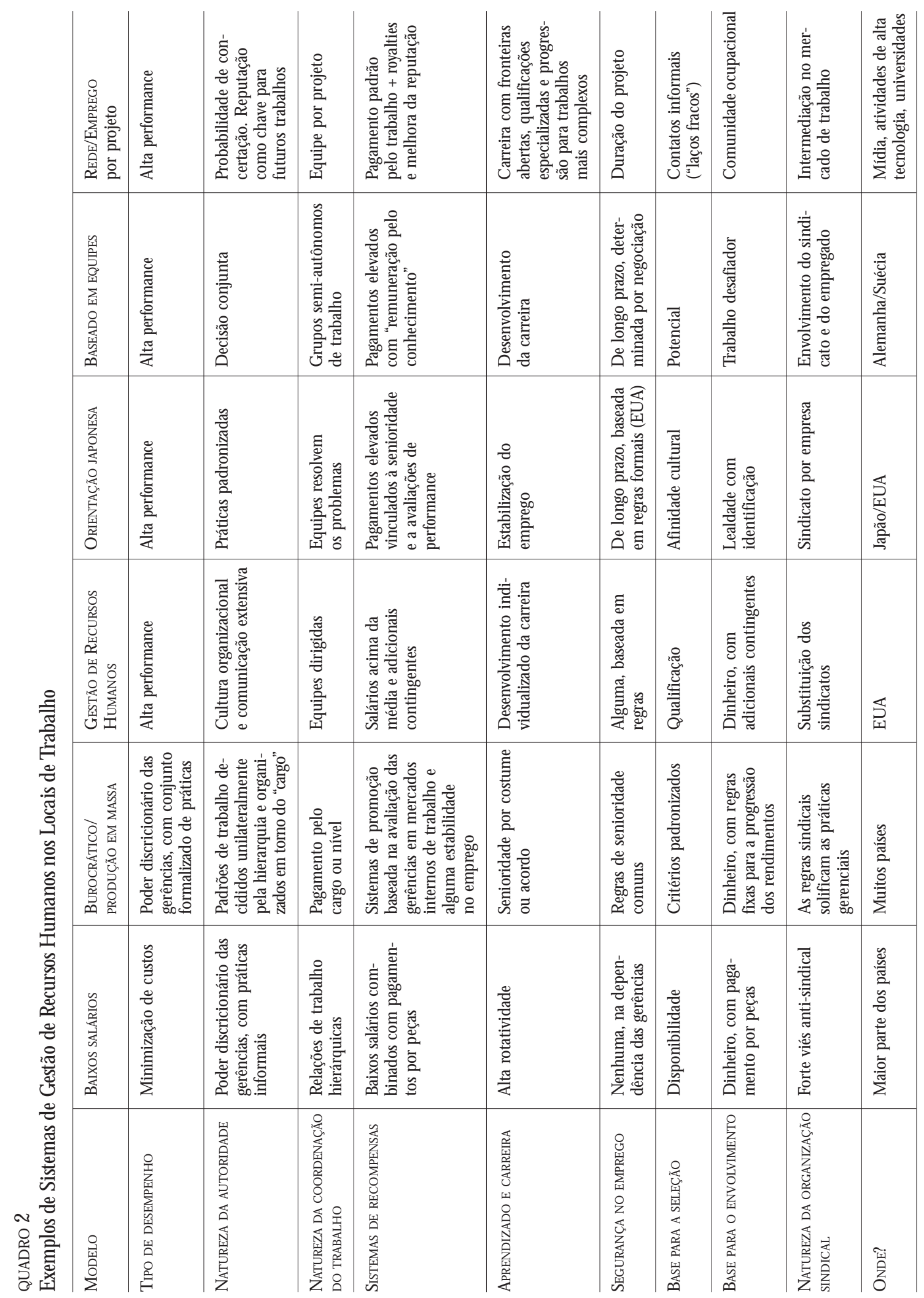


e outras não, há uma tendência natural favorável ao desempenho das primeiras em detrimento das últimas (cf. H olmstrom eM ilgrom, 1991).

É fácil reconhecer que uma das conseqüências dessa forma de organizar os cargos é um dualismo entre as tarefas de concepção e as de execução. Como cada trabal hador tem uma área específica de responsabilidade, a experiência e as habilidades que emergem do desempenho do cargo vão se desenvolver como o reflexo em um espelho e, habitualmente, os trabal hadores não irão formar um entendimento holístico dos objetivos gerais de seu trabalho, seja ele uma atividade de produção, seja um serviço. Seguindo-se a análise de H olmstrom e M ilgrom sobre multitarefas, podese ver que uma solução ótima, para a alta gerência, seria separar as tarefas produtivas de rotina, de um lado, das de coordenação e controle de qualidade, de outro. D essa forma, uma solução freqüente foi manter gerentes de linha especialistas e inspetores de qual idade especial istas, cujos desempenhos poderiam ser avaliados e recompensados separadamente.

Embora esta análise tenha focalizado certos aspectos de um fato estilizado, pode-se ver facilmente como as características básicas do sistema burocrático de gestão de recursos humanos permitem estabelecer limites à autoridade gerencial na regulação do conteúdo do contrato de emprego ex post.

À primeira vista, poderia parecer que sistemas de trabal ho de alta performance, especialmente os que têm padrões bem desenvolvidos de trabalho flexível, contrariam essa regra. Considerando-se que é controversa a extensão em que os modelos norte-americanos de sistemas de trabal ho ditos de "orientação japonesa" conseguiram realmente romper com o modelo tayIorista (alguns autores falam de um "taylorismo de equipe"), proponho tomar os sistemas de orientação japonesa na forma como eles ocorrem no próprio Japão. Como há mais consenso quanto ao alto grau deflexibilidade das tarefas que lá existe, isto torna mais robusto o teste do argumento a respeito dos limites para a autoridade das gerências no âmbito dessa relação de emprego.

U ma característica amplamente reconhecida sobre o organização do trabalho nas firmas industriais privadas do Japão é a substituição do posto de trabalho ou cargo, como unidade organizacional básica, pela área de trabaIho ou função (cf. Coriat, 1991; K oike, 1997). Em lugar da atribuição de cargos para trabalhadores individuais, grupos ou equipes assumem a responsabilidade por uma determinada área de trabalho. Um conjunto de características fundamentais contribui para restringir a má-fé das gerências no que diz respeito às prescrições de trabal ho. A primeira delas repousa no 
maior nível de risco ou de risco moral a que ambas as partes estão expostas. Ao contrário do que ocorre na situação de estreitas fronteiras de cargo, não há a rede de proteção representada por um desempenho mínimo prescrito ou por exigências máximas. $M$ ais do que isso, as gerências agora têm de lidar com equipes de trabal hadores que se constituem na base para o poder do grupo de trabalho, poder que, no sistema taylorista, os cargos individualizados e o monitoramento de desempenho seriam capazes de solapar. Isso eleva a dependência que as gerências têm de relações cooperativas de trabaIho. Assim, um elemento de estabilidade surge dos custos crescentes que assumiria para a gerência uma fratura na cooperação.

A segunda dessas características diz respeito a regras que dão uma estrutura estável para a equipe de trabal ho e para suas relações com a gerência. I sso constitui um suporte para a coerência interna do grupo de trabalho, a qual é, por sua vez, o fundamento tanto para o trabal ho flexível como para suas relações com a gerência. U ma prática amplamente difundida é hierarquizar os membros do grupo de acordo com as competências que adquiriram, que são função do leque de tarefas que a gerência reconhece que cada um pode desempenhar. D essa forma, os trabalhadores seniores podem de sempenhar um leque de tarefas mais amplo do que os juniores. Esse ordenamento protege os seniores da substituição por juniores e fornece a estes últimos um incentivo para que desenvolvam suas habilidades, com a ajuda dos primeiros. Koike (1994) descreve uma prática adotada comumente nas plantas japonesas, para dar suporte a esse intercâmbio: a matriz de classificação dos cargos é publicamente exibida. N ela, cada trabal hador pode verificar quais as habilidades que a gerência reconheceu nele, e como ele é ordenado em relação aos seus companheiros de trabalho. U ma proteção a mais contra o favoritismo gerencial (risco especialmente elevado quando se aposta pesadamente em avaliações subjetivas dos empregados) é dada pela rotação dos gerentes de linha entre diferentes grupos, o que possi bilita ao departamento de pessoal monitorar a consistência das avaliações dos empregados individuais.

N esse tipo particular de sistema de trabal ho de alta performance, os trabalhadores são progressivamente incentivados a ampliar o leque e a complexidade de tarefas que desempenham ao longo do tempo, o que traz para as gerências um benefício, no que tange à flexibilidade dos cargos. Ao encorajar a formação de grupos de trabalho, a gerência está criando uma base potencial mente mais poderosa para oposição e proporcionando aos trabaIhadores meios mais vastos de monitorar e controlar como sua autoridade 
é exercida na atribuição de tarefas, em contraste com o foco individualista do taylorismo.

A partir dessa vigorosa experiência de sistema de trabalho de alta performance, pode-se ver que o seu sucesso está ancorado na habilidade de prover um equivalente funcional às proteções com que os empregados contam no modelo burocrático. As escolhas das gerências quanto às práticas de $\mathrm{RH}$, em outras áreas, ficam limitadas, uma vez que essa solução tenha sido adotada. Se uma organização em equipe é adotada, e não há postos de trabalho individuais, então o papel das gerências delinha muda. 0 gerenciamento do desempenho também muda. $\mathrm{N}$ ão se podem medir resultados individuais numa equipe de produção, embora possam ser avaliados os comportamentos do trabalhador individual ante o grupo, como por exemplo o grau em quese demonstra cooperativo ou o quanto se dispõe a compartilhar com os colegas e com a gerência seu conhecimento e suas habilidades. D a mesma forma, recompensas vinculadas ao resultado individual fazem pouco sentido quando este não pode ser facilmente medido, de forma que elas passam a vincular-se a outros aspectos avaliados do desempenho ou aos resultados do grupo. Assim, podem-se apreender muitas das conexões existentes entre as diferentes práticas de $\mathrm{RH}$ que integram os distintos modelos descritos no Q uadro 2.

A discussão desenvolvida até aqui enfocou a forma como as soluções para o imperativo que compele à obrigatori edade influenciam a escolha das práticas de RH que a elas se vinculam. M as um segundo eixo de diferenciação se encontra na forma como o imperativo da eficiência é enfrentado. Isso envolve a distinção entre alinhar a organização do trabal ho a partir das demandas do sistema de produção ou a partir das habilidades que os trabal hadorestrazem consigo: as abordagens da produção e do treinamento, respectivamente. A abordagem do treinamento introduz uma nova dimensão, dado o critério adicional para identificar as áreas detarefas dos empregados, relacionadas às suas habilidades, particularmente no caso daquelas ocupacionais ou profissionais. A organização do trabalho artesanal, como é comum no ramo da construção civil em muitos países, eas burocracias profissionais seguem o tipo de abordagem centrada na tarefa, delimitando as frontei ras do trabal ho realizado por trabal hadores qualificados e profissionaisa partir de certos tipos-chave de tarefas. Já o trabal ho que envolveo uso das ferramentas ou de materiais do ofício tem sido usado como critério para estabelecer as fronteiras dos cargos no que concerne aos trabalhos manuais especializados. Distinções semelhantes estabelecem-se para o trabalho de 
diferentes empregados profissionais, eentreempregados profissionais e não profissionais.

U ma vez mais, tendo em vista a intensidade da discussão que transcorre nosE stados U nidos sobre o grau de diferenciação entreos model os apresentados no Q uadro 2, émais indicado tomar um exemplo robusto deambiente no qual é sabido que as habilidades ocupacionais são amplamente reconhecidas e podem, portanto, dar conta de levantar limites ao poder das gerências para prescrever a flexibilidade do trabalho. Algunsautorescitam a GM como exemplo de firma norte-americana que adota a abordagem baseada em equipes para sua gestão de recursos humanos no local de trabal ho, enquanto K atz e D arbishire (2000) destacam a Alemanha e a Suécia, em seu estudo internacional. Q uando as habilidades ocupacionais são utilizadas como meio para determinar as fronteiras dos cargos, advém uma série de conseqüências para a estrutura da gestão de recursos humanos no local de trabaIho. As relações na gerência de linha serão freqüentemente determinadas pela assimetria entre chefe e operador, quanto à competência técnica. Isso, muitas vezes, impede uma supervisão apurada, a menos que o gerente de linha detenha as mesmas habilidades. De qualquer modo, é normalmente mais econômico para a gerência delegar certa parcela da tomada de decisões, uma vez que os trabal hadores possuem as habilidades técnicas necessárias para fazer as escolhas apropriadas. $N$ ão é de esperar que a senioridade ocupe um papel central na alocação de trabalho e na progressão, tendo em vista a ênfase conferida ao treinamento reconhecido e à experiência como critérios de acesso ao trabal ho qualificado. D iferentemente da descrição estilizada dos sistemas de trabal ho japoneses, nos quais o grupo de trabal ho era relativamente homogêneo e estruturado com base na progressão por senioridade e competências para desempenhar tarefas, a ancoragem em habilidades ocupacionais tenderá a segmentar a força de trabalho em linhas ocupacionais, restringindo-se tanto as oportunidades de ascensão para os menos qualificados como as recompensas para as habilidades específicas à firma, em contraposição às habilidades ocupacionais.

T êm despertado crescente interesse, como uma nova variante de sistemas de $\mathrm{RH}$ de alta performance, 0 emprego baseado em projetos e a chamada "economia de redes", conforme atesta a temática central da Conferência de Berlim da Associação Internacional de Relações Industriais, ocorrida em 2003. D esse modo, qualquer teoria sobre a relação de emprego deveria buscar algum aporte analítico nesse tipo de arranjo contratual. A diferença fundamental entre esse tipo de emprego ea relação de emprego consagrada 
repousa na natureza transiente do primeiro, definida pela expectativa de duração de um projeto particular - como no caso das atividades de mídia, na realização de um filme, de um CD ou de uma peça publicitária. U ma característica importante dessas atividades, que as distinguem das formas mais tradicionais de auto-emprego - em que há um produto específico cuja entrega pode ser combinada antecipadamente, como no caso do trabalho autônomo de tradução (por exemplo, Fraser e G old, 2001) - , é que se espera que os trabal hadores envolvidos cooperem de maneira flexível. Essa é também uma característica que elas partilham com os sistemas de trabalho de alta performance. Embora a relação seja definida temporariamente, ela permanece em aberto quanto ao trabalho a ser desenvolvido (Baumann, 2003; H aunschild, 2003). N ão será essa uma demonstração de que as firmas conseguem contratar no mercado aberto a provisão de serviços específicos de que necessitam, preservando ainda a flexibilidade para adaptar o conteúdo desse trabal ho na forma que as suas gerências considerarem necessária?

Um exame mais detido das evidências disponíveis indica que essas relações de emprego "baseadas em projetos" são construídas sobre a base de proteções que são funcional mente equivalentes àquelas identificadas na relação típica de emprego. Elas fornecem incentivos e meios para reforçar a cooperação baseada na boa-fé, equivalentes verificados no emprego de duração indeterminada. D e fato, $\mathrm{H}$ aunschild (2003) caracterizou as relações de emprego baseadas em projetos por ele observadas no ramo teatral alemão como regidas por um "sistema interorganizacional de emprego". Baumann (2003) faz observações semel hantes, na sua comparação das indústrias cinematográficas britânica e alemã. Assim como Tolbert (1996) em seu estudo sobre os setores de alta tecnologia, eles assinalam a importância de normas ocupacionais, como um fator para conduzir a organização do trabalho, e de "comunidades ocupacionais", que aportam uma fonte decisiva de sanções contra o comportamento não cooperativo. A reputação, por si mesma, não tem suficiente adequação, uma vez que as pessoas podem fornecer informações falsas sobre o passado umas das outras, visando a denegrir competidores, enquanto no interior de uma rede social estabelecida tem-se meIhores meios de julgar a confiabilidade da fonte de tais informações. Além disso, há, muitas vezes, normas sociais e profissionais entre seus membros que contribuem para dar sustentação a um comportamento confiável. N esse tipo de emprego, há também, freqüentemente, incentivos financeiros alternativos aos salários propostos, como pagamentos de tipo royalty, que se 
acumulam com o uso comercial dos direitos de filmagem (Paul e Kleingartner, 1994), e opções de compras de ações que permitem, ainda, que o coordenador de um projeto projete a performance presente em re compensas futuras.

D essa forma, pode-se considerar que o modo como é regulada a flexibilidade no interior da relação de emprego exerce grande influência na configuração da estratégia de recursos humanos no local de trabalho. Em A theory of employment systems, sustentei que a satisfação dos dois imperativos contratuais forneceria uma condição necessária e suficiente para uma relação de emprego viável, aceitável tanto pela firma como pelo trabal hador. Se essas condições não fossem satisfeitas, pelo menos uma das partes sairia mais beneficiada se optasse por um quadro contratual alternativo. Ser necessário e suficiente significa que, no âmbito das proposições básicas aqui formuladas, pode-se fundamentar nesses dois imperativos uma tipologia exaustiva, de modo que, teoricamente, outras tipologias seriam redutíveisa ela $a^{3}$ N a tipologia ampliada dos modelos de gestão estratégica de recursos humanos, do Q uadro 2, o modelo de baixos salários e o modelo burocrático tomam parte nas abordagens "centrada na tarefa" e "produção"; 0 de orientação japonesa integra as abordagens "centrada na função" e "produção". 0 modelo baseado em equipes pertence à abordagem "treinamento" e, dependendo de quão flexível seja a regulação das fronteiras dos cargos, integrará seja a abordagem centrada na tarefa, seja a centrada na função. 0 modelo de gestão de recursos humanos, em decorrência do alto grau de controle gerencial, integraria a abordagem de tipo produção "centrada na tarefa". Astensões observadas no interior dessemodelo parecem indicar que, embora a gerência desejasse al cançar a flexibilidade característica da abordagem centrada na função, 0 al to grau de controle a traz de volta à abordagem centrada na tarefa (cf., por exemplo, Baraldi et al., 1995, sobre as experiências na França). Finalmente, muitas versões do modelo de emprego baseado em projetos, na forma como praticado nos setores de mídia, parecem combinar o controle centrado na função e a abordagem do treinamento.

Regulando a relação de emprego: o papel das instituições sindicais

Ao voltar-me para a contribuição das instituições sindicais na sustentação da relação de emprego, gostaria de enfocar o modo como a presença dessas instituições ajuda a reforçar a efetividade das regras de emprego, fornecendo-Ihes suporte. $D$ arei especial atenção à forma pela qual instituições
3. Em essência, isso diz respeito à escolha entre emprego eauto-emprego, racionalidade limitada, informação imperfeita e, ao menos parcialmente, interesses divergentes. 
interfirmas enriquecem o leque desanções que cada partepodeaplicar, com 0 objetivo de fazer valer o seu entendimento das regras de emprego. A renegociação é um momento especialmente problemático, já que os custos de desistência na relação tornaram a "saí da" uma opção cara. Entretanto, esseé apenas um dos aspectos de um elenco em que as instituições interfirmas podem incrementar a flexibilidade sob a qual opera a relação de emprego. Considerarei primeiramente al guns problemas comuns que surgem quando a negociação se dá em nível micro, ea seguir aquel es queaparecem especialmente sob a abordagem do treinamento. Em ambos os casos, a ação coletiva exerce um papel fundamental, por envolver atores que são externos à transação imediata e, assim, contribuem tanto para os benefícios individuais como para os coletivos, a partir de um mecanismo efetivo de coordenação: a relação de emprego.

\section{0 controle das externalidades na negociação em nível micro}

Embora as regras de trabalho apresentadas anteriormente resolvam 0 problema de definir os limites da autoridade gerencial sobre a atribuição de trabalho, elas próprias podem se tornar objeto de risco moral. Isso pode adquirir diversas formas:

- Q ualquer uma das partes pode tirar vantagem de assimetrias de informação, para impor sua interpretação de uma determinada regra.

- Pode haver ganhos mútuos com uma aplicação flexível da regra, sempre quando isso não seja usado para redefinir a própria regra.

- As mudanças nas circunstâncias econômicas requerem que as regras de trabalho sejam adaptadas periodicamente, e isso tem de ser efetivado sem que se reabram todos os elementos para renegociação.

- As regras de trabalho funcionarão de forma mais estável se seus princípios mais gerais forem codificados em algum tipo de acordo coletivo (por exemplo, em um acordo de classificação).

Boa parte das regras sociais cria espaço para que os indivíduos encontrem atalhos, que são atraentes precisamente porque todos os demais estão cumprindo a regra. M entir efurar a fila são bons exemplos. D esse modo, ostraba Ihadores podem entrar em uma relação de emprego com a expectativa de que a gerência irá respeitar o espírito de certas regras e deparar com o uso de todo o tipo de pretexto para justificar as mais variadas tarefas ou o aumento 
da carga de trabalho. De maneira análoga, os trabalhadores podem tirar vantagem do seu maior conhecimento etentar passar seus gerentes para trás (cf. alguns exemplos em Roy, 1952, e Burawoy, 1979). D eque forma trabaIhadores ou gerentes, individual mente, podem fazer cumprir aquilo queacreditam ser a interpretação justa? I sso écom freqüência difícil dentro das fronteiras de um local de trabalho específico. Por outro lado, se uma das partes pode convocar o apoio de uma organização externa, um sindicato ou uma associação de empregadores, então há espaço para quea disputa tomemaior vulto. Isso tem duas implicações importantes. Em primeiro lugar, eleva-sea capacidade desses grupos de trabalho ou gerentes individuais de acionar um suporteadicional e, assim, aumentam as potenciais sanções contra a aplicação oportunista de regras de trabalho. Esse fator, em si mesmo, pode aumentar a disposição de trabalhadores e gerentes em aceitar regras de trabalho específicas, já que eles se tornam mais confiantes de que uma interpretação justa pode ser assegurada. Em segundo lugar, qualquer coalizão externa dissiparia rapidamente sua força se tivesse de intervir a cada reclamação, o que torna necessário que ela seja seletiva. Com isso, sindicatos eorganizações de empregadores têm todas as razões para fazer um julgamento sobre quais reclamações de seus membros devem ser respal dadas e quais recusadas. Em decorrência, procurarão, geralmente, desencorajar os pleitos oportunistas. Assim, coalizões interfirmas, de trabal hadores e de firmas, podem contribuir de dois modos para a maior efetividade das regras de emprego: elas aumentam, em grupos específicos, a confiança de queépossível resistir a ações injustas da outra parte, e podem policiar as ações de seus próprios membros, desencorajando a má-fé.

0 apoio de instituições interfirmas também facilita a aplicação flexível de regras no local de trabalho. Um dos problemas dessa aplicação em um ambiente descentralizado, sobretudo quando as regras se encontram apenas parcialmente codificadas, é que o conteúdo real da regra pode se transformar ao longo do tempo, de modo que a flexibilidade de hoje se torne a norma de amanhã. Se o ponto de referência da regra está enraizado em relações vigentes no grupo de trabal ho, é difícil resistir a esse processo. Em contrapartida, se há um acordo coletivo ou uma norma informal cuja aplicação perpassa diversos locais de trabalho, como pode ser encontrado nas regras de demarcação de ofícios qualificados, conta-se, assim, com um ponto de comparação externo. Se as pessoas sabem que os fundamentos ou as linhas-mestras de sua cooperação não serão comprometidos pelo fato de trabal harem flexivelmente, é mais fácil que se disponham a fazêlo. 
4. A abordagem do treinamento não depende daexistênciaanterior de mercadosocupacionais. Isso foi demonstrado pelo modo como asgrandesfirmasalemãs, no final do século XIX, organizaram seuspróprios sistemas internos de treinamento-aprendizado, para fazer frente às inadequações do sistema de aprendizado preexistente (cf. Lutz, 1975). Ainda assim, sua efetividade éal tamente potencializada pelo estabelecimento demercados ocupacionais, quando mais não seja porque esses ajudam a criar familiaridadecom certostipos de regras de trabalho, tornando-as, assim, mais vigorosas.
A contribuição de instituições externas à firma pode, ainda, se dar na adaptação de regras de emprego a circunstâncias econômicas e técnicas em processo de mudança. É muito difícil para as partes conduzir esse tipo de negociação no local de trabalho, porque o resultado afeta a aplicabilidade das regras deemprego, o que por sua vez afeta o poder decada um dos lados de sustentar sua posição. Por isso, é muito mais seguro para grupos singulares recusar-se a negociar, ou pôr o pé no freio, e assim retardar a mudança. Renegociar regras de emprego torna-se maisfácil quando há o suporte desse tipo de instituição. U m exemplo eloqüente encontra-se nos acordos de flexibilidade holandeses, os quais, uma vez estabelecidos na cúpula, criaram um quadro de referência para a mudança no local de trabalho. Visser (1998) considera que isso possibilitou uma difusão muito rápida de práticas novas entre as firmas da $\mathrm{H}$ olanda, ao passo que a renegociação descentralizada dos termos do emprego se demonstrou vagarosa e irregular.

Por fim, as regras de classificação dos cargos, especialmente quando sua aplicação atravessa o conjunto de firmas, ajudam a conferir transparência à sua regulação. Elas respondem a um dos problemas fundamentais da organização econômica, destacado por Simon eW illiamson. Q uando os agentes econômicos são apenas limitadamente racionais, eles necessitam de uma linguagem com a qual possam enfrentar a complexidade da informação relativa aos cargos. I sso éfornecido pelas categorias das classificações de cargos, as quais, com efeito, determinam os critérios acordados para comparar cargos no interior das firmas e entre elas. São usadas tanto para determinar os níveis de remuneração para diferentes tipos de trabal ho como para definir padrões de trabalho, fixando o tipo de qualificação requerida para a contratação. Podem, ainda, orientar as pessoas, no interior das organizações, quanto às demandas de trabal ho e aos padrões de desempenho.

\section{0 controle das externalidades sob a abordagem do treinamento}

A abordagem do treinamento aplicada à organização do trabalho eà identificação das atribuições legítimas de tarefas toma as habilidades dos emprega dos como dadas, eao redor delas organiza os cargos eas atribuições de atividades. A presença de habilidades ocupacionais simplifica o número de problemas relativos à regulação de cargos, comparativamente à abordagem da produção, uma vez que o processo de treinamento ajuda a socializar os trabal hadores e os gerentes de linha no âmbito de normas aceitas para a distribuição de trabalho e para o desempenho no cargo ${ }^{4}$. 
Por outro lado, a abordagem do treinamento, tanto quanto os mercados ocupacionais a ela associados, é vulnerável a vários tipos de ação oportunista, que precisam ser controlados por instituições interfirmas. Como é bastante conhecido, Becker (1975) previu que os treinandos teriam de arcar com o custo de seu treinamento em habilidades transferíveis, pois precisamente essa transferibilidade implica que os empregadores não podem estar seguros de nenhum retorno de seus investimentos. $\mathrm{N}$ ão obstante, a maioria das pesquisas empíricas sobre custos de treinamento para o aprendizado de trabalhadores manuais mostra que, no cômputo geral, os custos bancados pelos empregadores são consideráveis, mesmo quando se leva em conta a baix xa freqüência com que os aprendizes são pagos e a contribuição produtiva deles durante o treinamento. Becker predisse que, sob tais condições, os empregadores reduziriam esse tipo de treinamento, e assistir-seia a um declínio tal qual o que ocorreu no treinamento de aprendizado na GrãBretanha, nas últimas décadas.

Boa parte dos argumentos levantados pelos economistas para explicar por que os empregadores, ainda assim, pagam por treinamento geral e transferível depende da existência de al gum tipo de "adesão", atribuída sobretudo a problemas informacionais. Entretanto, isso pode ser contornado quando se trata de habilidades certificadas. Por isso, o papel decisivo da regulação institucional dos mercados ocupacionais reside em controlar qualquer tendência à "deserção" por parte de empregadores individuais. Sem sustentação institucional, os mercados ocupacionais são instáveis, já que, quanto maior a escassez de habilidades, maiores os incentivos a "roubar" trabal hadores alheios e menores os incentivos a oferecer treinamento geral. 0 declínio do treinamento de aprendizado na Grã-Bretanha, em contraste com sua contínua vitalidade na Alemanha, ilustra esse processo (cf. $M$ arsden, 1995).

A oferta, pelo empregador, de treinamento em habilidades ocupacionais acarreta desvantagem competitiva somente se algumas firmas treinarem e outras não. Em decorrência, se o elevado envolvimento das firmas é mantido, a tentação para o comportamento oportunista será mais fraca. D o mesmo modo, é mais fácil impor sanções a um pequeno número de "caronas" do que a um grande número deles. Assim, assegurando-se que uma elevada proporção global detreinamento possa ser sustentada, torna-se possível evitar um círculo vicioso no qual os cortes efetuados pelo empregador no treinamento produzam escassez de habilidades, o que por sua vez elevaria 0 incentivo ao comportamento "carona", gerando ainda mais escassez. 
O s mercados ocupacionais requerem, também, outras formas de suporte institucional, para funcionar. Se os custos devem ser compartilhados, então os treinandos precisam estar seguros de que os empregadores irão oferecer vagas condizentes para eles, eépreciso que haja, ainda, um grau suficiente depadronização dos conteúdos e dos modelos detreinamento. D essemodo, chega-se, tanto pelo lado do empregador como pelo do empregado, à necessidade de uma infraestrutura institucional que dê suporte ao funcionamento dos mercados ocupacionais e, assim, à abordagem do treinamento no âmbito da relação de emprego.

As evidências relativas à nova modalidade do emprego baseado em projetos sugerem que é mais adequado interpretá-lo como submetido a pressões da abordagem do treinamento, tendo em vista sua debilidade de vínculos com qualquer firma ou organização em particular. Isso pode ser claramente observado na contribuição de Tolbert (1996) para a "carreira sem fronteiras". Tanto essa autora como outros que depois dela escreveram enfatizaram o papel das "comunidades ocupacionais", que desempenham funções parecidas com as de outros corpos organizacionais mais formalmente constituídos. Em essência, trata-se de redes sociais de indivíduos interligados por uma vinculação ocupacional compartilhada, laços de socialização e muitas vezes, também, interesse econômico. N os casos em que os membros compartilham um conjunto de qualificações, percebe-se que têm em comum o interesse de que sua reputação de competência e confiabilidade possa se sustentar e não seja comprometida por oportunistas (cf. $M$ arsden, 2004). 0 papel das comunidades ocupacionais nas atividades de mídia também se sobressai claramente nas pesqui sas realizadas na Alemanha (cf., por exemplo, Sydow e Staber, 2002).

Efeitos sobre o comportamento e sobre a estrutura das instituições sindicais

A seguir, abordo o suporte que a ação coletiva oferece aos dois imperativos contratuais: como eleva a obrigatoriedade das regras de transação e como torna mais eficiente 0 ajuste entre as qualificações e as demandas de trabal ho. Já que um dos objetivos fundamentais das instituições sindicais é defender os interesses dos seus membros quanto ao emprego, é lícito esperar que suas formas de atuar dêem sustentação às necessidades da relação de emprego.

As contribuições mais importantes de instituições abrangentes, interfirmas, até aqui discutidas, assentam-se na forma como elas: 
- Proporcionam sanções coletivas para ajudar a impor regras de transação e de classificação no interior da empresa, tornando-as assim mais previsíveis.

- O ferecem os canais para a renegociação.

- Contribuem para reforçar a confiança, no local de trabalho.

- Dão suporte a mercados ocupacionais e, em menor grau, a mercados internos de trabalho.

Q uetipos deestruturas institucionais podem proporcionar essesuporte? Q uando se combinam os dois imperativos contratuais, podem-se identificar as modalidades de padrão de representação trabalhador-empregador que melhor sustentam cada uma das estratégias de gestão de recursos humanos anteriormente apresentadas (ver Q uadro 3). A demanda por uma forte representação no local de trabalho é maior para as duas regras "baseadas na função". D e fato, sólidas garantias para os trabal hadores no local de trabalho parecem uma condição necessária para o sucesso das regras baseadas na função e, na maioria das circunstâncias, uma forte coordenação interfirma é necessária para 0 sucesso da abordagem do treinamento ${ }^{5}$. 0 maior nível de especificação das fronteiras, na organização centrada nas tarefas, sob a abordagem da produção, significa que, embora a ação coletiva possa ser benéfica, ela não é essencial. D essa forma, nas grandes firmas japonesas, que combinam as abordagens "baseada na função" e "produção", predomina uma forma muito ativa de sindicalismo de empresa. Em grandes firmas alemãs, os conselhos de fábrica desempenham um papel central, lidando com um grande número de questões relacionadas aos cargos. O s conselhos de fábrica franceses oferecem um interessante contraexemplo. U tilizando a regra do posto de trabalho centrado na tarefa, as firmas francesas sentem menos necessi dade de uma estreita cooperação no local de trabalho. Ademais, em boa parte do período pós-guerra, a competição política entre os sindicatos, ao lado da debilidade da base sindical, fez com que os consel hos de fábrica não tivessem, na França, a capacidade de desempenhar o mesmo papel que possuíam na Alemanha. Assim, como Lorenz (1995) observa, os conselhos de fábrica franceses têm sido menos antagônicos e menos efetivos do que seus correspondentes alemães.

No que diz respeito à abordagem da produção, em confronto com a abordagem do treinamento, uma forte coordenação interfirmas desempe nha um papel-chave no sentido de conter as pressões oriundas de "caronas". M ercados ocupacionais desregulados estão sempre expostos aos riscos dos
5. Logicamente, a abordagem do treinamento podeexistir no interior de uma firma isolada como parece ter sido 0 caso das firmas industriaisalemãsquetomaram a dianteira e modernizaram o sistema de aprendizado, no final do século XIX -, mas o modelo rapidamente se estendeu para o conjunto das firmas. 
oportunistas, devido às pressões comuns que induzem os empregadores a arcar com parte dos custos necessários para oferecer treinamento em habilidades ocupacionais. Essas pressões freqüentemente derivam das restrições de oferta, nos casos em que se espera que o financiamento fique a cargo dos treinandos e de suas famílias, especialmente quando se trata das famílias mais pobres. U ma vez que os empregadores assumem uma parte substancial desses custos, há incentivos para que outrasfirmas assumam comportamentos oportunistas, "roubando" os trabal hadores que os competidores treinaram. A regulação coletiva, pelas partes interessadas, garante uma solução comum para esse problema. D essa forma, na Alemanha, organizações locais de empregadores dão muita sustentação aos sistemas de aprendizado de seus trabalhadores, manuais ou de escritório. A Grã-Bretanha oferece um interessante contra-exemplo, nesse aspecto. D urante décadas, houve lá um bem-sucedido sistema de aprendizado e vigorosos mercados ocupacionais, mas o seu declínio nas décadas de 1970 e 1980 mostrou-se decorrente, em grande parte, da fraqueza do quadro institucional de que dependiam (cf. $M$ arsend, 1995). A debilidade da coordenação por parte dos empregadores conduziu a uma maior dependência de regras centradas nas tarefas para manter o sistema em funcionamento. Essas regras foram avidamente defendidas pela organização sindical de trabalhadores qualificados, muito embora, progressivamente, por secções ocupacionais especiais, no interior desindicatos mais gerais. Tais regras obrigaram muitos empregadores a treinar aprendizes, já que não podiam substituir facilmente trabalhadores qualificados que haviam tido treinamento de aprendizado. Isso demonstrou ser uma desvantagem econômica considerável para as firmas e, com isso, seu interesse no aprendizado declinou, abrindo o campo para seu virtual colapso, a partir da metade dos anos de 1980.

À primeira vista, o padrão de organização sindical por ramos, na Alemanha, pareceria também em desacordo com 0 argumento. Entretanto, como Sengenberger (1987) demonstrou, muitas das habilidades ocupacionais cobertas por sistemas de aprendizado são específicas de certos setores, em particular quando se considera o leque extremamente amplo de ramos e setores na organização sindical e de empregadores daquele país. Assim, ainda que os sindicatos al emães sejam organizados "por ramos", em termos de sua abrangência, eles, diferentemente dos sindicatos com cobertura semelhante em outros países, dão um extraordinário poder aos trabal hadores ocupacionalmente qualificados, cujo status especial é consagrado nos acordos salariais e de classificação. Esses acordos são muito minuciosos ao defi- 
nir até que ponto trabal hadores sem aprendizado podem progredir na direção do status de trabalhadores qualificados, com base no treinamento no posto de trabalho.

Por fim, embora a representação interfirmas possa não ser essencial para o funcionamento da abordagem da produção, há bons exemplos de como ela pode elevar sua flexibilidade. $\mathrm{Na}$ França, onde $\mathrm{o}$ sistema de postos de trabal ho tem ampla difusão, acordos setoriais de classificação forneceram um quadro de referência para a renegociação de normas de qualificação na empresa (cf. Eyraud et al., 1989). N o Japão, o estudo de Cole (1989) sobre a disseminação de círculos de controle de qual idade como resultado deuma ação coordenada entre as firmas ilustra, igualmente, como esse tipo de ação pode promover mai or flexibilidade dos cargos. Emboratenha sido conduzido pelos empregadores, Cole sustenta que o movimento assumiu muitas características "de massas", em decorrência da coordenação informal entre as firmas, a qual não foi alcançada nos Estados U nidos. Na última seção desteartigo, examino as relações de emprego nos ambientes mais fracamente institucionalizados, de firmas em que os sindicatos não estão presentes.

QUADRO 3

OsQ uatroT i posdeRegrasdeTransação eosPadrõesdeRepresentaçãoTrabalhador-Empregador

\begin{tabular}{l|l|l}
\hline \multirow{2}{*}{ RePRESENTAÇÃo NO LOCAL DE TRABALHO } & \multicolumn{2}{|c}{ REPRESENTAÇÃo INTERFIRMAS } \\
\cline { 2 - 3 } & FraCA & FoRTE \\
\hline FRACA & Posto de trabalho & Regra do território do cargo \\
\hline FORTE & H ierarquia de competências & Regra da qualificação \\
\hline
\end{tabular}

\section{0 modelo de postos de trabalho e os locais de trabalho "não sindicalizados"}

D ada a menor necessidade de ação coletiva, o modelo de postos de trabaIho é aquele que tem mais probabilidade de florescer em locais de trabal ho fracamente institucionalizados e nos quais não há a presença dos sindicatos. $N$ esses casos, os problemas de assimetria de informação, racionalidade limitada e interesses parcial mente divergentes continuam a demandar solução, e as regras de transação seguem sendo essenciais para a relação de emprego.

A probabilidade de que 0 sistema de postos de trabal ho predomine repousa em duas observações. Poder-se-ia esperar que as regras centradas na tarefa fossem o tipo preferido pel os trabal hadores. Elas oferecem uma defi- 
nição mais clara dos papéis no trabalho e das responsabilidades de cargo, capacitando os trabal hadores a identificar mais facilmente potenciais pressões que seus gerentes de linha exerçam para exigir mais. É também mais fácil para os trabal hadores monitorar o gerenciamento de desempenho seas obrigações de trabalho estiverem relativamente codificadas. As regras centradas na função tendem a não ter o mesmo apelo, já que as obrigações de trabal ho dos empregados se encontram, nelas, muito indeterminadas. Ademais, a ausência de organização coletiva, tanto entre empregados como entre empregadores, torna menos provável que mercados ocupacionais estáveis se constituam. Isso irá empurrar as firmas na direção da abordagem da produção, e não da do treinamento. C onsiderados conjuntamente esses fatores, justifica-se a expectativa de que o tipo de regra baseado no posto de trabal ho predomine. Ele é o que melhor lida com os problemas de oportunismo no interior da relação de emprego, na falta de fortes instituições dos trabal hadores e dos empregadores. D esse modo, a ausência de um quadro coletivo apropriado ajudaria a explicar a difusão lenta e irregular dos "modelos norte-americanos de alta performance" e a persistência de modelos tayloristas de organização naquele país (cf. Appelbaum e Batt, 1994; K atz e D arbishire, 2000).

Como os outros tipos de regras de emprego, o sistema de postos de trabalho pode ser administrado com diversificados graus de flexibilidade. Argumentou-se anteriormente que a ação coletiva pode facilitar o trabal ho flexível e, mais importante do que isso, contribuir para a renegociação dos princípios da organização do trabalho. N a sua ausência, as firmas e os trabalhadores continuam se defrontando com a necessidade de se ajustar a mercados em transformação. Q uais mecanismos, então, encontram-se abertos para eles?

Em primeiro lugar, pode-se esperar que os empregados minimizem seus investimentos na firma, porque os amarram e os expõem à renegociação oportunista por parte dos seus empregadores. Se não têm condições de deixar o emprego, encontram-se, então, em uma frágil posição para a barganha. $\mathrm{Na}$ ausência de negociação coletiva, a melhor proteção para um trabalhador é uma oferta de emprego de um empregador rival. Conseqüentemente, é de supor que os trabalhadores deixarão a cargo das firmas parte considerável do investimento em desenvolvimento de habilidades, e que as firmas, por sua vez, privilegiarão habilidades específicas a elas.

Em segundo lugar, há vias alternativas, individuais, para a renegociação das atribuições de trabalho. Para os trabalhadores de carreira, as firmas 
podem vincular essa questão às promoções, usando-as como uma oportunidade para alterar as atribuições de trabal ho, mas precisam também elevar o salário. É possível que haja a necessidade de as firmas serem mais específicas no que diz respeito às oportunidades de promoção quando contratam trabal hadores em um ambiente desse tipo, uma vez queé menor a probabilidade de que acreditem em promessas indeterminadas quando o empregador enfrenta menos auditorias e balanços. Sobre esse ponto, é significativa a descoberta de Baron et al. (1986) de que, nas firmas em que não há atuação sindical, as progressões de cargos eram mais estruturadas do que nas firmas sindicalizadas.

Em terceiro lugar, as firmas podem usar o processo de rotatividade para ajustar os papéis no trabal ho por meio da negociação individual, a menos que uma negociação dessa natureza venha a ocorrer mediante novas contratações, o que pode ser importante pelo fato de as carreiras oferecerem incentivos somente para um pequeno percentual de trabal hadores. $D$ e acordo com Layard, N ickell e Jackman (1991, p. 222), aproximadamente $30 \%$ dos empregados nos Estados U nidos tinham sido contratados menos de um ano antes, contra $20 \%$ no Reino U nido e cerca de $10 \%$ na França ${ }^{6}$. A referência a esse espaço de tempo, no entanto, fornece apenas uma indicação aproximada, eé necessário lembrar que a economia norte-americana conta também com uma significativa proporção de empregos de longa duração. $\mathrm{N}$ ão obstante, 0 dado sugere que depender fortemente da negociação individual pode levar a prescrições de tarefas mais rígidas, que por sua vez conduzem a menores tempos de permanência nos empregos, com os conseqüentes custos de recrutamento e treinamento para os empregadores.

Finalmente, a renegociação individual dos cargos, quando generalizada, pode resultar numa firma periodicamente em "estado de emergência", situação associada, por exemplo, a um enxugamento em resposta a um mau de sempenho no mercado de ações. Entretanto, isso pode ser uma faca de dois gumes. Como o estudo de Bewley (1999) salientou, mesmo nos Estados U nidos muitos empregadores relutam em anunciar cortes de pessoal, pois, ainda que possam favorecer concessões, podem também causar um colapso no estado de ânimo dos empregados.

\section{Conclusão}

Este artigo formulou 0 argumento segundo 0 qual o foco, tanto das análises sobre relações industriais como sobre a gestão de recursos huma-
6. 0 s dados referem-se ao ano de 1988, queintegra um período de baixo desemprego, entre o pico de 19821983 eaquele que teve lugar no início dosanos de 1990. 
nos, precisa ser redirecionado para as características centrais da relação de emprego, especialmente para as condições que devem ser satisfeitas para que as firmas assim como os trabal hadores se beneficiem desse quadro de referência flexível que lhes permita cooperar. 0 impulso empírico para esse exercício originou-se deduasfontes. A primeiraéo declínio ea reformulação das instituições de representação col etiva nos mercados de trabal ho, mesmo em países onde elas demonstraram ser fortes até muito recentemente, como é o caso da Alemanha e também do Japão e da U nião Européia. A segunda fonte vem das evidências cada vez maiores no sentido de que, do mesmo modo que não houve um modelo universal de organização "taylorista", hoje não há nenhum padrão universal entre os "sistemas de trabalho de alta performance". Em verdade, pesquisas recentes sobre "gestão estraté gica de recursos humanos", como as compiladas por Scherer e Leblebici, indicam uma persistente diversidade.

A primeira parte deste ensaio estabeleceu os principais elementos da relação de emprego como uma instituição social. Sublinhou-se o leque de diferentes soluções que podem limitar o controle das gerências sobre a flexibilidade do trabalho, em grau suficiente para que os trabal hadores considerem atrativo 0 emprego e para que ambas as partes se beneficiem dessa estrutura contratual. D efendeu-se a posição de que a satisfação dos dois imperativos contratuais fundamentais - que as regras de trabalho que delimitam a autoridade da gerência, a um só tempo, sejam coercitivas em sua obrigatoriedade e que garantam a correspondência entre as habilidades dos trabal hadores eas demandas de trabal ho dos empregadores - dá origem a quatro tipos básicos de regras de trabalho. Essas, sustentou-se aqui, são os pilares de diferentes tipos de sistemas de trabal ho, associados a diferentes modelos de gestão estratégica de recursos humanos. Isso ocorre porque, ao se delimitar a autoridade da gerência, configura-se uma hierarquia gerencial no local de trabalho, um modo de gerenciamento do desempenho, dos cargos, da formação de habilidades e da natureza da interdependência entre os trabal hadores.

A segunda parte procurou identificar os tipos de arranjos institucionais interfirmas que possibilitam que as regras de trabal ho funcionem mais efetivamenteno âmbito do local detrabal ho, potencializando, assim, os ganhos, tanto para os trabal hadores como para seus empregadores. A esse respeito, pode-se pensar nas external idades associadas a cada uma dessas regras e nas diferentes formas que as tornam vulneráveis como fatores que suscitam, nos trabal hadores e nas firmas, a demanda por diferentes tipos de organização coletiva. 
U ma importante questão que permanece em aberto éo grau de influência exercido por essas regras de trabalho sobre a evolução dos padrões de gestão dos recursos humanos e sobre as instituições sindicais de forma mais geral. Há, claramente, influências históricas significativas, e a lei e outras instituiç̃oses sociais podem aportar outros princípios de organização social e econômica. Está claro, também, que a relação de emprego por tempo indeterminado é, ela mesma, um quadro de referência historicamente contingente para a cooperação econômica. Como M ottez (1966) demonstrou em seu magistral levantamento histórico, a relação de emprego surge como forma dominante apenas a partir do final do século XIX einício do século XX. Ademais, o trabalho da O CDE mostra que tanto as firmas como os trabaIhadores transitam entre o emprego e 0 auto-emprego, o que comprova a presença constante da escolha a esse respeito. $\mathrm{N}$ a minha "teoria dos sistemas de emprego", sustentei que os diferentes padrões de relação de emprego podem sedifundir de um modo totalmente descentralizado, muito embora não seja sempre essa a forma como eles se espraiam. I sso pode ocorrer porque, uma vez que uma regra específica se torna dominanteem um determinado ambiente, é mais fácil usá-la para reger a cooperação do que tentar impor outra, diferente. $\mathrm{Q}$ uando as pessoas estão familiarizadas com uma regra e nela confiam, os resultados se tornam mais previsíveis e a obrigatoriedade a que são compelidos se torna mais fácil de ser lograda. D essa forma, pode-sedizer quequanto mais vigorososforem esses ganhos, maisforte será a pressão por al gum tipo de isomorfismo, no âmbito de um determinado setor ou região, e, em conseqüência, maior a influência exercida sobre a evolução dos sistemas de gestão dos recursos humanos adotados nas firmas e sobre a evolução da estrutura das instituições sindicais.

Referências Bibliográficas

Appelbaum, E. \& Batt, R. (1994), The new American workplace: transforming work systems in the U nited States. Ithaca, N .Y., Cornell U niversity Press.

BaraldI, L.; D um asy, J.-P. \& T Roussier, J.-F. (1995), "Accords salariaux innovants et théorie du salaire". É conomie Appliquée, 48 (4): 105-137.

Baron , J.; D avis-Blake, A. \& Bielby, W. (1986), "The structure of opportunity: how promotion ladders vary within and among organizations". Administrative Science Q uarterly, 31 (2): 248-273, jun.

Baron, J. N .; Burton, M . D . \& H annan, M. T. (1996), "Theroad taken: theorigins 
and evolution of employment systems in emerging high-technology companies". Industrial and Corporate Change, 5: 239-276.

. (1999), "Engineering bureaucracy: the genesis of formal policies, positions, and structures in high technology firms". Journal of Law, Economics and Organization, 15: 1-41.

Baum ann, Arne. (2003), Path-dependency or convergence?T heemergence of labour market institutions in the media production industries of the $U \mathrm{~K}$ and $\mathrm{G}$ ermany. Dissertação de mestrado, Florence, European University Institute.

BECKER, G. S. (1975), H uman capital: a theoretical and empirical analysis, with special reference to education. Chicago, University of Chicago Press.

BewLey, Truman. (1999), Why wages don't fall during a recession. Cambridge, M ass., $\mathrm{H}$ arvard U niversity Press.

BuRAwOY, M . (1979), M anufacturing consent: changes in thelabor processunder monopoly capitalism. Chicago, University of Chicago Press.

CLARK, J. (1993), "Full-flexibility and self-supervision in an automated factory". In: CLARK, J. (ed.). H uman resource management and technical change. Londres, Sage. COASE, R. H . (1937), "The nature of the firm". Economica, 16 (4): 386-405, nov. CoLE, R. (1994), "D ifferent quality paradigms and their implications for organisational learning”. In: Aokı, M \& \& D oRE, R. (eds.). TheJapanesefirm: the sources of compeitive strength. 0 xford, 0 xford University Press.

Cole, R. E. (1989), Strategies for learning: small group activities in American, Japanese, and Swedish industry. Berkeley, University of California Press.

Coriat, B. (1991), Penser à l'envers. Paris, Christian Bourgois.

Crozier, M . (1963), Le phénomène bureaucratique. Paris, Seuil.

D ugué, E. (1994), "La gestion des compétences: les savoirs dévalués, lepouvoir occulté". Sociologie du Travail, 3 (94): 273-292.

Eyraud, F.; J obert A.; Rozenblatt, P. \& T allard, M . (1989), Lesclassificationsdans I'entreprise: production deshiérarchies professionnelleset salariales. D ocument Travail Emploi. Paris, M inistério do Trabalho, do Emprego e da Formação Profisssional. Fraser, Janet \& GoLd, M ichael. (2001), "'Portfolio workers': autonomy and control amongst freelance translators". Work, Employment \& Society, 15 (4): 679-697.

H AunsCHILD, Axel. (2003), “M anaging employment relationshipsin flexiblelabour markets: the case of German repertory theatres. Human Reations, 56 (8): 899-929, ago.

H OLMSTROM , B. \& M ILGRoM, P. (1991), “M ultitask principal-agent analysis: incentive contracts, asset ownership, and job design". The Jornal of Law, Economics and Organization, vol. 7.

J OBERT, A. (1990), Les grilles de classification professionnelle: quelques repères historiques". CFDT Aujourd'hui, 99:6-14, dez. 
Katz, H . \& DARbishiRe, O . (2000), Converging divergencies: worldwide changes in employment systems. Ithaca, ILR Press/Cornell University Press.

KoIKE, K. (1994), "Learning and incentive systems in Japanese industry". In: Ao KI, M. \& D ORE, R. (eds.). Thejapanesefirm: the sources of competitivestrength. O xford, O xford University Press. . (1997), H uman resource development. Tóquio, Japan Institute of Labour, Japanese Economy \& Labor Series, 2.

LAYARD, R.; N ICKELL, S. \& Jackm AN, R. (1991), U nemployment: macroeconomic performance and the labour market. 0 xford, 0 xford U niversity Press.

Lorenz, E. (1995), "Promoting workplace participation: lessons from Germany and France". Industrielle Beziehungen, 2 (1): 46-63.

LUTZ, B. (1975), Krise des Lohnanreizes: ein empirisch-historischer B eitrag zum Wandel der Formen betrieblicher $\mathrm{H}$ errschaft am B eispiel der deutschen Stahlindustrie. Frankfurt, Europäische Verlagsanstalt.

M ARSDEN, D. W. (1995), "A phoenix from the ashes of apprenticeship? Vocational training in Britain". International Contributions to Labour Studies (suplemento do Cambridge Journal of Economics), 5: 87-114. (1999), A theory of employment systems: micro-foundations of societal diversity. O xford, O xford U niversity Press.

M AURICE, M .; M AN NARI, H .; T AKEOKA, Y. \& IN O KI, T. (1988), D esentreprisesfrançaises et japonaisesface à la mécatronique: acteurset organisation dela dynamiqueindustrielle. Aix-en-Provence, Laboratoire d'Economie et de Sociologie du Travail (C N RS).

M ottez, B. (1966), Systèmes de salaire et politiques patronales: essai sur l'évolution des pratiqueset desidéologies patronales. Paris, CentreN ational dela RechercheScientifique. O ECD. (1992), Employment Outlook 1992. Paris, OECD.

Paul, A. \& K Leingartner, A. (1994), "Flexible production and the transformation of industrial relations in the motion picture and television industry". Industrial and Labor Relations Review, 47 (4): 663-678, jul.

Reynaud, B. (1992), Le salaire, la règle et le marché. Paris, Christian Bourgeois.

Roy, D. (1952), "Q uota restriction and goldbricking in a machine shop". American Journal of Sociology, 67 (2): 427-44.

Sengenberger, W. (1987), Strucktur und Funktionsweise von Arbeitsmärkten: die Bundesrepublik D eutschland im internationalen Vergleich. Frankfurt, C ampus Verlag. Sherer, P. D. \& Leblebicl, H. (2001), "Bringing variety and change into strategic human resource management research". Research in Personnel and H uman Resources M anagement. Greenwich, C.T., Elsevier, 20: 199-230.

SIM ON , H . A. (1951), "A formal theory of the employment relationship". Econometrica, 19 (3): 293-305, jul. 
Slichter, S. (1919), T he turnover of factory labor. N ova York, Appleton.

Slichter, S.; H ealy, J. \& Livernash , E. (1960), Theimpact of collectivebargaining on management. Washington D. C., Brookings Institution.

Sydow, Jörg \& Staber, Udo (2002), "The institutional embeddedness of project networks: the case of content production in German television". Regional Studies, 36 (3): 215-227.

Tolbert, P. \& Zucker, L. (1983), "Institutional sources of change in the formal structure of organizations: the diffusion of civil service reform, 1880-1935". Administrative Science Q uarterly, 28 (1): 22-39, mar.

T O LBERT, P. (1996), "O ccupations, organizations, and boundaryless careers". In: ART HUR, M . \& RousSeAu, D . (eds.). The boundaryless career: a new employment principle for a new organizational era. N ova York, O xford U niversity Press, pp. 331-349.

VISSER, J. (1998), "Two cheers for corporatism, onefor the market: industrial relations, wage moderation and job growth in the N etherlands". British J ournal of Industrial Relations, 36 (2): 269-292, jun.

W ILLIAM SON , O . E. (1975), M arketsand hierarchies analysisand antitrust implications. N ova York, Free Press.

Yamanouchu, T. \& O Kazaki-W ard, L. (1997), "Key issues in H RM in Japan". In: TYSON, S. (ed.). T he practice of human resource strategy. Londres, Pitman.

ZUCKER, L. (1991), "M arkets for bureaucratic authority and control: information quality in professions and services". Research in the Sociology of O rganizations, 8: 157-190.

\section{Resumo}

Sistemas de emprego, estratégias de gestão e instituições do trabalho 0 artigo sublinha a importância do estudo da dinâmica da relação de emprego para o entendimento das mudanças recentes tanto na gestão de recursos humanos no mercado de trabalho, como nas instituições sindicais. A relação de emprego é uma instituição socioeconômica que deve satisfazer os interesses daquel es que a adotam, sejam firmas, sejam trabal hadores. $\mathrm{N}$ a primeira parte, examina-se a estrutura da relação de emprego e os requerimentos para a sua viabilidade. $N$ as duas partes seguintes, procura-se mostrar como o entendimento antes estabelecido afeta a compreensão da dinâmica de diferentes tipos de sistemas de gestão de recursos humanos nos locais de trabalho e como ele impõe um novo foco à abordagem das instituições sindicais, eassim, ao fazê lo, explora-se como aplicar essa linha de análise ao estudo de formas de emprego emergentes, como o "emprego baseado em projeto", o qual, à primeira vista, poderia ser entendido como um desafio aos fundamentos da relação de emprego. 
Palavras-chave: Sistemas de emprego; Relação de emprego; G estão de recursos humanos; O rganização do trabalho.

\begin{abstract}
Employment systems: workplace human resources management strategies and labor institutions

The article argues that we need to pay more attention to the dynamics of the employment relationship if we are to understand current developments in labour markets human resource management, and labour institutions. The employment relationship is a socio-economic institution which has to satisfy the joint requirements of those who adopt it, both firms and workers. In the first section of the paper, I examine the structure of the employment relationship and the requirements that it must satisfy in order to be viable. In the next two sections, I trace out how this view affects our understanding of the dynamics of different kinds of human resource management systems at the workplace level, how it should refocus our approach to labour institutions, and in doing so, I also explore how the analysis can be applied to some of the emerging employment patterns, such as "project-based" employment, which at first sight might appear to challenge its foundations.

Keywords: Employment systems; Employment relationship; H RM ; Labour institutions; Work organisation.
\end{abstract}

Texto recebido em 05/ 2004 e aprovado em 08/2004.

$D$ avid $M$ arsden éprofes sor de Relações IndustriaisnaLondon School of Economics, E-mail: d.marsden@lse.ac.uk. 